\title{
Estudos Internacionais Sobre Valor Justo (2000-2016): Temáticas, Métodos e Sugestões de Pesquisas Futuras
}

\section{Resumo}

Objetivo: Analisar as publicações sobre valor justo nos principais periódicos internacionais de contabilidade e classificálas de acordo com temáticas e tipologias de pesquisa.

Método: O estudo corresponde a uma revisão de literatura descritiva e de escopo, nos moldes de Paré, Trudel, Jaana e Kitsiou (2015), sendo a amostra composta por 111 artigos publicados, no período de 2000 a 2016, nos trinta journals mais relevantes, segundo Matherly e Shortridge (2009).

Resultados: Identificou-se tendência crescente na produção científica sobre o tema, especialmente após 2011, com destaque nos cinco principais journals internacionais de contabilidade. A área de pesquisa se mostrou heterogênea, com publicações em diferentes temas, porém com destaque para: (i) comparação do valor justo com outros métodos de avaliação; e (ii) reações do mercado de ações ao valor justo. Ainda, observou-se a predominância de estudos quantitativos e com base em archival Contribuições: A união de diferentes estudos, métodos e abordagens sobre o valor justo condensa as principais pesquisas na área, contribuindo para a compreensão do debate e, principalmente, para observação do fenômeno da utilização do valor justo, que não é consensual do ponto de vista teórico e prático.

Palavras-chave: Valor Justo; Revisão de literatura; Pesquisa em Contabilidade; IFRS 13; SFAS 157.

\author{
Eduardo Bona Safe de Matos \\ Doutorando em Controladoria e \\ Contabilidade pela Universidade de São \\ Paulo (USP) e Professor na Universidade \\ de Brasília (UnB). Contato: Campus \\ Universitário Darcy Ribeiro, Prédio \\ da Face, Sala BT2 54/7, Asa Norte, \\ Brasília(DF), CEP: 70910-900. \\ E-mail: eduardobona@unb.br
}

Lucas Vieira Lôbo de Araújo Bacharel em Ciências Contábeis pela Universidade de Brasília (UnB). Contato: Campus Universitário Darcy Ribeiro, Prédio da Face, Sala BT2 54/7, Asa Norte, Brasilia(DF), CEP: 70910-900. E-mail: lukwolf@hotmail.com

\section{Mariana Guerra}

Doutora em Administração pela Universidade de Brasília (UnB) e Professora na Universidade de Brasília (UnB). Contato: Campus Universitário Darcy Ribeiro, Prédio da Face, Sala BT2 54/7, Asa Norte, Brasília(DF), CEP: 70910-900.

E-mail: profamarianaguerra@gmail.com

\section{Fernando Dal-Ri Murcia}

Doutor em Contabilidade e Controladoria pela Universidade de São Paulo (USP) e Professor na Universidade de São Paulo (USP). Contato: Avenida Professor Luciano Gualberto, 908, FEA 3, Sala 237, Cidade Universitária, São Paulo(SP),

CEP: 05508-010.

E-mail: murcia@usp.br 


\section{Introdução}

A Contabilidade, ao longo de sua existência, tem se adaptado às mudanças dos mercados, de forma a disponibilizar informações acuradas e relevantes aos seus usuários (Iudícibus \& Martins, 2007). Essas adaptações abrangem, inclusive, os métodos de avaliação e mensuração de ativos e passivos, ampliando-se a discussão sobre esses métodos, entretanto, somente a partir do século XX. Em destaque, os debates enfocam o conceito de valor e as contradições apresentadas entre custo histórico e valor justo (Martins, 2000; Iudícibus, Martins \& Carvalho, 2005). Para Lustosa (2016), com a evolução dos mercados e das transações econômicas, é possível observar não só mudanças de contexto, mas também de paradigmas, uma vez que, consoante Barley e Haddad (2007), passou-se do padrão de mensuração pelo custo histórico para valor justo.

Essa transição motivou, em 2006, ao Financial Accounting Standards Board (Fasb) a emitir a SFAS 157 - Fair Value Measurement -, pronunciamento este que trata especificamente da avaliação a valor justo, agrupando em um mesmo documento conceitos e estruturas de mensuração antes apresentadas em diversos pronunciamentos do Fasb. A proposta era de esclarecer e tornar mais consistente a aplicação do conceito (Barth, 2007), sendo observado, a partir de então, o aumento no número de publicações relacionadas ao tema. No âmbito das normas internacionais, o International Accounting Standards Board (Iasb) emitiu, em 2011, a IFRS 13 - Fair Value Measurement, que no cenário brasileiro corresponde ao Pronunciamento Técnico CPC 46 - Mensuração do Valor Justo.

Outro destaque no debate sobre valor justo é a crise financeira iniciada em 2007/08, que levou a discussões relacionadas à influência exercida pela contabilidade por valor justo no cenário econômico, e até que ponto a aplicação desse conceito aumentou os efeitos da crise (Markarian, 2014). Devido aos diversos questionamentos, o Fasb ainda publicou a SFAS 157-4, reafirmando a SFAS 157, porém lançando alterações no modelo de mensuração que permitiriam às entidades apresentar demonstrações com números próximos aos do período pré-crise (Lustosa, 2016). Outras discussões sobre o valor justo remetem à questão da sua relevância para a instauração da crise (Markarian, 2014) e a influência da crise na forma de utilização do valor justo (Goh, Li, Ng \& Yong, 2015).

Marra (2016) entende que a importância da discussão do conceito do valor justo deve-se à dicotomia no entendimento daqueles que são a favor ou contra esse método. Há ainda o debate sobre a utilização do valor justo por parte dos divulgadores de informação: se oportunista ou realmente informativa (Blacconiere, Frederickson, Johnson \& Lewis, 2011); ou seja, se a informação com base no valor justo é realmente relevante aos usuários (Whittington, 2008; Valencia, Smith \& Ang, 2013).

Uma das principais críticas à aplicação do valor justo decorre de sua subjetividade na ausência de mercados líquidos para a mensuração de ativos e passivos. Nesses casos, a marcação a mercado (mark to market) acaba sendo substituída pela marcação a modelo (mark to model). A marcação se torna ainda mais subjetiva no chamado nível três, em que as premissas utilizadas na mensuração não são observáveis, isto é, quando são definidas pela própria administração da empresa. Esse cenário possibilita a utilização do valor justo de forma oportunística, o que prejudica a qualidade da informação contábil (Bryan \& Lilien, 2013).

A não conformidade na prática da mensuração a valor justo pode, inclusive, evidenciar a necessidade de melhorias nas próprias características qualitativas do conceptual framework. Há, portanto, relevância acadêmica neste tema amplamente debatido, cuja definição conceitual ainda não é consenso (Barth, 2007). Considerando que as pesquisas abordam de forma distinta a aplicação do conceito e podem enfocar diferentes facetas do valor justo, e que, ainda, não existem trabalhos que exaurem a revisão literária do tema, questiona-se: quais são as principais temáticas, métodos e características das publicações sobre o valor justo nos principais periódicos internacionais de contabilidade?

O objetivo deste trabalho é, portanto, analisar os artigos sobre valor justo publicados nos principais periódicos internacionais de contabilidade e classificá-los de acordo com as temáticas e tipologias de pesquisa. Ainda, as características referem-se a autorias e fontes das publicações. Ressalta-se que não se trata de estudo de natureza bibliométrica ou sociométrica, ou ainda de um estudo epistemológico, mas, sim, de revisão de literatura descritiva e de escopo, nos moldes de Paré, Trudel, Jaana e Kitsiou (2015) (cf. Seção 3). 
Além da importância para professores, pesquisadores e profissionais, o estudo justifica-se por contribuir para a literatura científica ao caracterizar a pesquisa realizada sobre o valor justo nos últimos 16 anos (2000 a 2016) pelo meio acadêmico internacional. Esse período de análise inicia-se no ano de criação do IASB, órgão que defende o processo de reconhecimento e defesa do valor justo, passando, portanto, por períodos de construção do conceito, críticas e crise financeira, até os dias atuais. A seleção dos periódicos internacionais, por sua vez, foi baseada em Matherly e Shortridge (2009), que realizam uma avaliação e ranqueamento dos principais journals internacionais da área contábil.

O artigo encontra-se dividido em cinco seções. A presente introdução é seguida pela revisão da literatura, na qual se apresenta as principais discussões sobre valor justo nas pesquisas internacionais. Após, descrevem-se os procedimentos metodológicos. Na seção quatro, apresentam-se os resultados e suas análises. Por fim, tem-se considerações finais e sugestões de pesquisas futuras.

\section{Revisão da Literatura}

A partir do desenvolvimento do método das partidas dobradas, por volta do século XII, a contabilidade por custos históricos tornou-se predominante, passando por adaptações e avanços, até o surgimento e a aplicação do valor justo (Iudícibus \& Martins, 2007). Richard (2005) trata o fair value (termo em inglês para valor justo) como uma inovação, ou até mesmo revolução, na Contabilidade.

Apesar de o conceito e a aplicação do valor justo estarem normatizados, não há consenso entre os pesquisadores (Barth, 2007). Destaca-se, inclusive, que os conceitos apresentados pelo Fasb e Iasb foram motivos de significativa discussão e rejeição no meio acadêmico (Iudícibus, Martins \& Carvalho, 2005). A despeito disso, como método de mensuração de ativos e passivos, o valor justo pode ser expresso como o valor resultante de uma transação em que nenhuma das partes pode impor sua vontade (Niyama \& Silva, 2008).

\subsection{Principais discussões sobre valor justo}

As publicações têm se concentrado em três principais temáticas: (i) o debate sobre confiabilidade, utilidade e benefícios do valor justo; (ii) as diferenças entre este e os demais métodos de mensuração, segundo as normas publicadas; e, (iii) as influências do valor justo em diversas áreas do mercado e da Contabilidade (Barth, 2007). No presente estudo, especificamente, dá-se enfoque à primeira, predominante pelo volume de publicações. Cumpre destacar que, na contextualização que se segue, revisam-se também as publicações participantes da amostra deste trabalho, ou seja, os artigos vinculados aos 30 journals internacionais de Contabilidade mais relevantes segundo Matherly e Shortridge (2009).

\subsubsection{Normatização do valor justo}

Os debates sobre as regras de contabilização por valor justo cresceram após a crise financeira iniciada em 2007/08 (Lustosa, 2016), porém a discussão e teorização sobre o tema acontecem há mais tempo (Richard, 2005). Nas últimas décadas, os principais pontos de interesse das pesquisas sobre a normatização do valor justo têm sido os pronunciamentos do Iasb e Fasb, em geral, apontando possíveis efeitos dessas normas no meio contábil (Song, Thomas \& Yi, 2010; Bolívar \& Galera, 2012; Goncharov \& Triest, 2014) ou aspectos das normas (Elad, 2004; Jiang, Wang, \& Xie, 2015). Whittington (2008), por exemplo, critica ao afirmar que as normas sobre valor justo consideram mercados perfeitos sendo esses, na verdade, ligeiramente imperfeitos e, portanto, desconsiderados no contexto normativo. 
A edição do SFAS 157, por sua vez, também é objeto de estudo, a exemplo de Magnan, Menini e Parbonetti (2015) e Lustosa (2016). Entretanto, o interesse da academia se expande às outras SFAS, em pesquisas que abrangem temas específicos da Contabilidade, como os estudos de Beatty e Weber (2006) e Jarva (2009), que analisam a SFAS 142 - Goodwill and Other Intangible Assets -, em uma abordagem relacionada ao valor justo.

Outro foco tem sido a interação da normatização do valor justo com a administração governamental. Galdini e Grossi (2014), Song, Thomas e Yi (2010) e Bolívar e Galera (2012) analisam como o método de mensuração fair value afeta a contabilidade pública. Já Palea (2015) analisa a relação da normatização do valor justo com os governos em nível de bloco econômico, com aplicação na União Europeia.

\subsubsection{Efeitos e relações internas à entidade}

Pesquisas têm sido feitas sobre valor justo em relação a temas que abrangem a relação do fair value com decisões internas nas entidades e a relação daquele com estas. Os estudos vão desde a análise do valor justo como método de avaliação de certas contas ou operações (Goncharov \& Triest, 2014) às comparações entre o valor justo e outros métodos (Quagli \& Avallone, 2010; Christensen \& Nikolaev, 2013).

Sobre a interação do valor justo com análises de créditos/riscos, Gray (2003) atesta que as normas contábeis sobre fair value causam más mensurações dos riscos/taxas de juros, e tal efeito é também identificado em Gaynor, Mcdaniel e Yohn (2011), ao afirmarem que essas normas são contra intuitivas, podendo levar a erros em análises de créditos por parte dos usuários. Em contraponto, Lachmann, Stefani e Wohrmann (2015) afirmam que mudanças recentes nas normas diminuíram os riscos de mensurações e interpretações erradas, ainda que tais problemas continuem existindo.

Já sobre dividendos, outro ponto de discussão, Goncharov e Triest (2011) afirmam ter uma relação negativa entre ajustes ao valor justo e mudanças nos dividendos. Ainda, em publicação posterior, Goncharov e Triest (2014) atestam, após um estudo de caso, que mudanças nas normas de valor justo afetaram a política de dividendos de forma a causar omissões de partes destes. Relacionado a omissões, Bryan e Lilien (2013) demonstram que o valor justo, em combinação com estruturas contábeis não inseridas no balanço, podem permitir tripla contagem de renda.

Pesquisas dos últimos 16 anos têm comparado o valor justo a outros métodos. Nesse aspecto, Christensen e Nikolaev (2013), ao compararem a usabilidade do valor justo e do custo histórico no mercado, entendem que o primeiro tem uso limitado na contabilidade de ativos não financeiros, indicando que o fair value provavelmente não se tornaria o método padrão de forma voluntária. Linsmeier (2013) afirma que isso se deve à relevância do valor justo e do custo histórico na renda e não a problemas na confiabilidade do valor justo. Ainda sobre a comparação entre métodos, Danbolt e Rees (2008) afirmam que a relevância da adoção do valor justo pode variar dependendo das planilhas e informações disponíveis aos usuários.

Em relação à informação proporcionada pelo valor justo, Khurana e Kim (2003) defendem que o custo histórico é mais informativo que o fair value em relação a empréstimos e depósitos bancários; relação endossada por Cantrell, Mclnnis e Yust (2014), ao afirmarem que o custo histórico é mais útil do que o valor justo em prever clientes incobráveis futuros, empréstimos não pagos e insolvências bancárias, em curto e longo prazo. Em contraste com estes estudos, Liang e Riedl (2014) afirmam que o valor justo melhora a capacidade de se preverem os balancetes, apesar de reduzir previsibilidade do resultado líquido. 


\subsubsection{Efeitos e relações externas às entidades}

Há ainda estudos sobre a relação do valor justo com os efeitos externos às entidades. Embora focados na normatização em si, Jiang, Wang e Xie (2015), por exemplo, analisam a reação do mercado à renúncia do presidente do Fasb, que poderia vir a afetar as propostas de normas de valor justo, concluindo que o mercado reagiu de forma positiva a renúncia, principalmente os bancos que seriam mais afetados pelos novos requerimentos do valor justo para empréstimos. Ainda sobre reações externas ao valor justo, So e Smith (2009) afirmam que os preços de mercado, valor de mercado de ações e a expectativa de retorno de investimento por partes dos investidores são maiores quando as mudanças em relação a utilização do valor justo são evidenciadas nas publicações contábeis, resultado este corroborado por Robinson e Burton (2004), que observam reação significantemente positiva do mercado aos anúncios por parte das empresas sobre a adoção do valor justo como método de avaliação das concessões de opções de ações a funcionários.

A recente crise financeira motivou estudos sobre a relação do valor justo com esse acontecimento. Sobre o tema, Bowen e Khan (2014) sugerem que a razão da crise financeira ter acontecido não é diretamente o valor justo como método de avaliação, mas seria a forma que investidores e administradores entenderam e se adaptaram às mudanças das normas de valor justo, assim como dividem a responsabilidade pela crise com a política gerencial dos bancos em relação à liquidez de seus ativos. Já Markarian (2014) sugere que, apesar de o cenário de crise ter levado a crítica ao uso do valor justo e apontá-lo como culpado pelo acontecimento, a comparação entre valor justo e valor histórico já é um tema antigo. Argumenta, ainda, que mudanças recentes na normatização do fair value, feitas pelo Iasb e pelo Fasb diminuíram a confiabilidade do método.

A interação de empresas de auditorias e de auditores com o tema valor justo também é objeto de pesquisa dos últimos anos. Em relação aos honorários de auditoria, Goncharov, Riedl e Sellhorn (2014) afirmam que a utilização do valor justo, em geral, resulta em custos de monitoramento menores, sendo que as reduções nesses honorários variam conforme as características das demonstrações financeiras publicadas. Os resultados desse estudo contrastam com Ettredge, Xu e Yi (2014), que sugerem que os esforços de auditoria aumentam com a verificação de bens mensurados por valor justo, de forma que a utilização desse método proporciona aumentos nos honorários de auditorias. Griffin (2014) afirma que auditores toleram maiores distorções nas demonstrações financeiras publicadas quando os clientes proveem a eles relatórios adicionais, de forma que essa preferência das auditorias por informações suplementares por parte dos clientes pode afetar o reconhecimento de bens pelo valor justo nas demonstrações financeiras das empresas. Também em relação a como as auditorias encaram o valor justo, Lilien, Sarath e Schrader (2013) sugerem que as publicações e o disclosure do valor justo não estão sendo feitos de forma suficientemente rigorosa.

Por fim, as contribuições de estudos que envolvem efeitos externos à entidade podem ser visualizadas como contributivas ao mercado e reguladores, expondo como a mensuração por valor justo o afeta e aprimorando o conhecimento científico a partir da aplicação prática de seus conceitos.

\section{Procedimentos Metodológicos}

O presente estudo caracteriza-se como revisão de literatura descritiva e de escopo (Paré, Trudel, Jaana \& Kitsiou, 2015). A revisão de escopo procura demonstrar o potencial e os aspectos categóricos da literatura sobre alguma temática, assim como a natureza de algum tópico de pesquisa, sem a necessidade de adentrar especificamente nas produções, estando interessado em um conhecimento mais amplo da literatura. Para tanto, não se intenta, aqui, a análise da qualidade da produção, mas, sim, o levantamento da literatura por meio de análises de conteúdo e temáticas. Assim como a de escopo, a descritiva também não objetiva avaliar a qualidade dos estudos, mas, sim, determinar a extensão dos estudos que poderiam auxiliar na compreensão de tendências, proposições, teorias, metodologias (Paré, Trudel, Jaana \& Kitsiou, 2015). Essas revisões consistem, portanto, na coleta de pesquisas, codificação e análise numérica dos dados que refletem as frequências dos tópicos, autores e métodos das publicações analisadas. 
Nesse sentido, enfocaram-se aqui os artigos sobre o tema valor justo publicados nos periódicos internacionais de contabilidade mais relevantes em língua inglesa. Para definir esses periódicos e, por consequência, os analisados na pesquisa, o trabalho se baseou no modelo de estimação de qualidade de publicações de Matherly e Shortridge (2009). Dentre os journals selecionados, salientam-se as exclusões: (i) Journal of Accounting Literature (2000 a 2012), por não disponibilizar em formato digital artigos datados de antes de 2013; e (ii) Journal of Taxation, por não estar disponível para consulta em meios eletrônicos.

Para seleção da amostra foram consultados e catalogados artigos publicados durante 16 anos. A coleta de dados ocorreu em dois momentos. As publicações de 2000 a 2014 foram coletadas nos meses de julho e agosto de 2015. Em janeiro de 2017, coletaram-se dados de 2015 e 2016. Assim, a amostra abrangeu os anos completos de 2000 a 2016, com as devidas exceções já citadas. Ainda, todos os artigos dos journals selecionados foram tabulados utilizando-se como fonte os próprios sites dos periódicos e, posteriormente, selecionaram-se aqueles que continham, em seus títulos, as expressões "fair value" ou "fair-value". Esse procedimento foi preferível à procura em bases de dados, uma vez que nem todos os journals de interesse estão indexados nas bases disponíveis para consulta. Ao final desses procedimentos, a amostra ficou composta por 111 artigos científicos, sendo essa classificada, em relação às temáticas dos artigos, em Macro e Microcategorias (Figura 1), criadas a partir de Barth (2007).

\begin{tabular}{ll}
\hline \multicolumn{1}{c}{ Macrogrupos } & \multicolumn{1}{c}{ Microgrupos } \\
\hline \multirow{2}{*}{ Normatização do Valor Justo } & Normas sobre Valor Justo \\
\cline { 2 - 2 } Efeitos e Relações Internas às Entidades & Aplicações das Normas Contábeis de Valor Justo \\
\cline { 2 - 2 } & Efeitos da Aplicação do Valor Justo em Contas/Operações Específicas \\
\cline { 2 - 2 } & Efeitos relacionados às Escolhas da Administração \\
\cline { 2 - 2 } & Comparação do Valor Justo com outros Métodos de Avaliação \\
\hline \multirow{3}{*}{ Efeitos e relaçõos do Valor Justo em Passivos } \\
\cline { 2 - 2 } & Análise de Riscos e Valor Justo \\
\cline { 2 - 2 } & Reações do Mercado de Ações ao Valor Justo \\
\cline { 2 - 2 } & Relação entre Auditores e Auditorias e Valor Justo \\
\cline { 2 - 2 } & Valor Justo e a Crise Financeira \\
\hline
\end{tabular}

Figura 1. Macro e Microgrupos temáticos de classificação

Fonte: elaboração própria.

Barth (2007) sugere exemplos de área gerais relativas às pesquisas em fair value, baseando-se nas recentes discussões acadêmicas. Esses exemplos motivaram a criação de três Macrogrupos [temáticos] para classificação dos artigos analisados no presente estudo. Mas, para maior detalhamento, esses foram subdivididos em dez Microgrupos ( $c f$. Figura 1), considerando para sua definição abordagens e objetivos gerais de cada publicação.

Assim, o primeiro Macrogrupo abrange Normatização do Valor Justo e engloba os artigos que tiveram como objeto principal estudar o processo de normatização do tema, que inclui tanto a edição e publicação das normas, quanto sua aplicação posterior. Os artigos classificados no Migrogrupo - Normas sobre Valor Justo - tratam das normas editadas pelo Fasb e Iasb, revisando conceitos, características e histórico, como em Barlev e Haddad (2007), que analisam a relação entre a harmonização contábil internacional e a contabilidade do valor justo.

No Microgrupo Aplicações de Normas Contábeis de Valor Justo, foram alocados os artigos que analisam as normas contábeis que tratam de valor justo buscando direcionar a utilização dessas a diferentes ambientes contábeis, como pode ser observado em Bolívar e Galera (2012), que analisam a capacidade do valor justo de melhorar a contabilidade governamental, por meio de transparência contábil. 
O segundo Macrogrupo Efeitos e Relações Internas às Entidades agrupa os estudos que analisaram aspectos do valor justo que afetam internamente as entidades, como seu gerenciamento e política contábil. Nesse, o Microgrupo Efeitos da Aplicação do Valor Justo em Contas/Operações Específicas tem como base de pesquisa a relação entre o valor justo e sua utilização em determinados grupos de contas do ativo e resultado, como em Israeli (2015), que analisa os efeitos financeiros da aplicação do valor justo em propriedades para investimentos.

No Microgrupo Efeitos Relacionados à Escolha da Administração, foram classificados os artigos que estudam o efeito do valor justo em decisões proferidas pelos diretores e administradores, como em Chen, Tan e Wang (2013), ao realizarem experimentos com contadores, a fim de examinar como a contabilidade por valor justo afeta as decisões econômicas de gerentes.

Já Comparação do Valor Justo com Outros Métodos de Avaliação engloba os trabalhos que relacionaram as características do valor justo com as de outros métodos de avaliação, tanto apresentando semelhanças ou diferenças, quanto analisando as vantagens ou desvantagens desses métodos em diferentes situações. O estudo de Khurana e Kim (2003) representa um exemplo dessa classificação, ao comparar a capacidade dos métodos de avaliação valor justo e custo histórico em explicar valores patrimoniais.

O Microgrupo Aplicação do Valor Justo em Passivos (Fair Value Option) foi separado do grupo de contas/operações específicas por se tratar dos efeitos e análises do impacto do valor justo sobre o passivo das entidades, denominado liabilities fair value option. Um exemplo é o estudo de Wu, Thibodeau e Couch (2016), que verificam os efeitos da contabilização de passivos pelo valor justo na assimetria informacional (seleção adversa).

Por fim, o terceiro Macrogrupo Efeitos e Relações Externas às Entidades agrupa as pesquisas que abordam temas relacionados a fenômenos externos às entidades em si, ou seja, ao ambiente que as engloba. Nesse, no Microgrupo Análise de Riscos e Valor Justo, foram classificados os trabalhos cujo foco era a relação do valor justo com análises e instrumentos de risco, a exemplo de Hirst, Hopkins e Wahlen (2004), que analisam como a contabilização de renda pelo método do valor justo afeta a análise dos riscos acionários de bancos comerciais.

Reações do Mercado de Ações ao Valor Justo é o Microgrupo no qual foram classificados os estudos sobre o comportamento do mercado de ações e suas mudanças com a utilização e adoção do valor justo, como pode ser observado na pesquisa de Koonce, Nelson e Shakespeare (2011), que elaboram experimentos para analisar a visão de investidores em relação ao valor justo.

Os artigos classificados em Relação entre Auditores e Auditorias e Valor Justo relacionam o tema "valor justo" com a área de auditoria. Neste Microgrupo há artigos que analisam o quanto a contabilidade por valor justo dificulta o trabalho de auditorias e em como isso afeta honorários e, também, como auditorias tratam a contabilidade por valor justo. Um exemplo é o trabalho de Brink, Tang e Yang (2016), que realizam experimentos para verificar fatores que influenciam os julgamentos dos auditores a respeito das estimativas baseadas em valor justo.

Por último, no Microgrupo Valor Justo e a Crise Financeira foram classificados os artigos que tratam da relação do valor justo com a crise financeira instaurada nos últimos anos, como o trabalho de Goh et al. (2015), que analisam a evidenciação de ativos financeiros contabilizados por valor justo durante a crise financeira.

Além da análise temática, principal aspecto para categorização no presente estudo, foram realizadas análises metodológicas adaptadas do framework teórico de Smith (2003), a fim de possibilitar maior detalhamento descritivo. Assim, os artigos foram caracterizados por métodos de pesquisa e, também, em qualitativos e quantitativos. Nesse momento, a preocupação dos autores relacionava-se à classificação com base no método e nas abordagens utilizadas para as respostas ao objetivo principal das pesquisas, não se consideranado a classificação com base na descrição e apresentação dos resultados. Identificaram-se, também, a origem dos autores e as características gerais de autoria. Os métodos de categorização metodológicas foram: (1) Archival (engloba estudos de natureza quantitativa, como análises de séries temporais e cross-section, e estudos de outras naturezas, como análises de conteúdo e de discurso); (2) Caso de ensino; (3) Estudo de caso; (4) Experimento; (5) Framework (proposições de frameworks teóricos); (6) Normativo (estudos de natureza crítica sobre normas); e (7) Revisão de literatura. 


\section{Resultados, Análises e Discussões}

Os resultados dividem-se na apresentação dos artigos quanto às temáticas abordadas e quanto à tipologia de pesquisa utilizada. Além disso, busca-se caracterizar os autores e suas origens institucionais, assim como os periódicos e suas representatividades.

\subsection{Temáticas dos artigos e crescimento ao longo do tempo}

A Figura 2 demonstra a produtividade de artigos por Macrogrupos ao longo do tempo. A Tabela 1, mais adiante, apresenta a variação da produção de forma mais detalhada, com as quantidades e Microgrupos. As análises incluirão resultados numéricos e percentuais (não incluídos na tabela por questões operacionais).

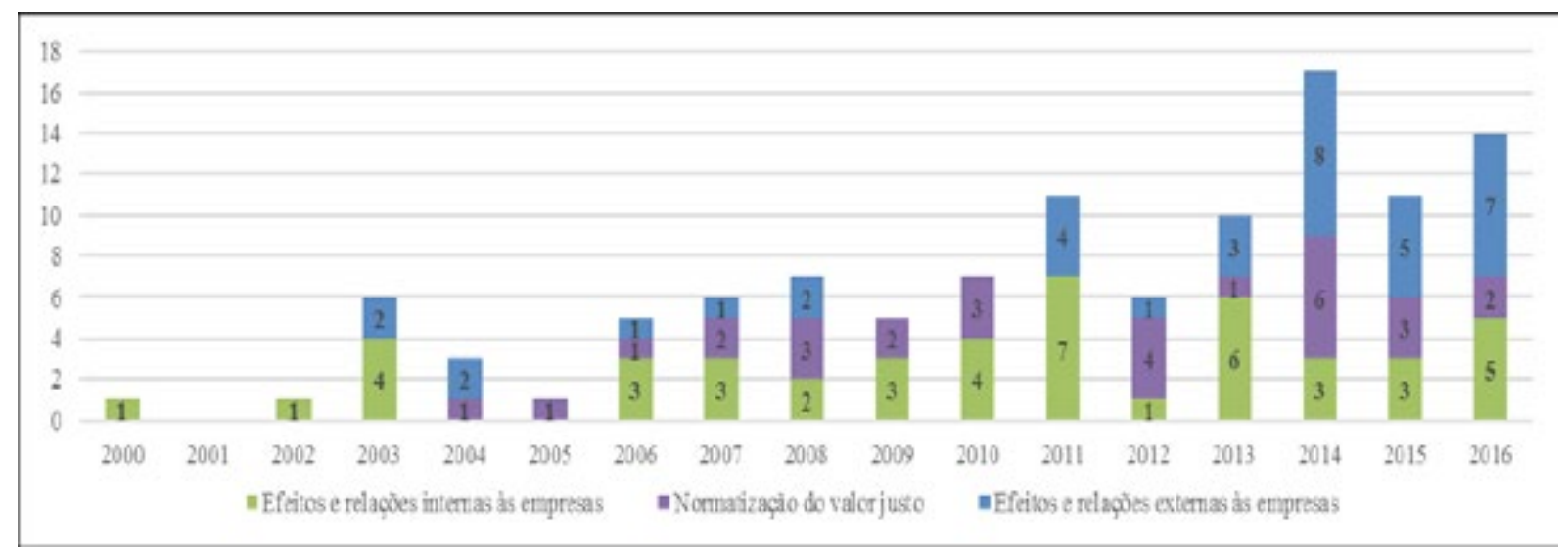

Figura 2. Produção anual por Macrogrupo

Fonte: elaboração própria.

Em uma análise conjunta da Figura 2 e da Tabela 1, observa-se o crescimento médio do número de publicações ao longo dos anos, em especial a partir de 2006, ano em que (i) a SFAS 157 (norma emitida pelo Fasb sobre fair value measurements) foi lançada e (ii) o Iasb emitiu o discussion paper, iniciando o processo normativo que culminou na IFRS 13 (fair value measurement), em 2011. Outro destaque é 2011, quando o crescimento das publicações também é superior à média dos anos anteriores.

Outros fatos que podem ser observados são com relação às variações em cada um dos Macrogrupos. Ao se analisar o tema Normatização do Valor Justo, observa-se que a primeira produção estudada ocorreu em 2004. Nota-se, aqui, a relação com a normatização norte-americana, marcada em junho/2003 pelo início do processo de realização da SFAS 157. Após isso, as publicações nesse tema foram constantes, com maior quantidade em 2012 e 2014, momento em que já havia normas americana e internacional editadas.

Nos primeiros anos da amostra, observam-se publicações sobre os Efeitos e Relações Internas às Entidades. Uma vez que o valor justo já era discutido por normatizadores, estando presente em diferentes normas emitidas, entende-se que, nesses estudos, já procurava-se verificar se esse método de mensuração teria efeitos internos nas organizações, sendo as publicações nesse tema representativas na maioria dos anos da amostra. 
Por fim, os artigos sobre Efeitos e Relações Externas às Entidades estão mais concentrados e presentes nos anos finais da amostra. Essa visualização demonstra que o estudo dos efeitos de mercado e crise foram mais presentes a partir de 2012, momento em que as normas já estavam editadas e, principalmente, após 2013, momento em que a IFRS 13 se tornou de aplicação mandatória e os efeitos decorrentes poderiam ser estimados com maior confiabilidade. Não há publicações classificadas nesse Macrogrupo, nos anos de 2009 e 2010, fato que pode ser explicado pelas incertezas do mercado decorrente da crise financeira, fazendo com que artigos produzidos anteriormente pudessem ser refutados pelos eventos econômicos ocorridos e artigos novos ainda não pudessem capturar os efeitos das mudanças, criando, assim, um gap nesse grupo de publicações.

Tabela 1

Classificação de artigos por Macro e Microgrupos por ano (2000 a 2016)

\begin{tabular}{|c|c|c|c|c|c|c|c|c|c|c|c|c|c|c|c|c|c|c|}
\hline $\begin{array}{c}\text { Grupos (macro e micro) } \\
\text { / ano }\end{array}$ & 00 & 01 & 02 & 03 & 04 & 05 & 06 & 07 & 08 & 09 & 10 & 11 & 12 & 13 & 14 & 15 & 16 & Total \\
\hline $\begin{array}{l}\text { Normatização do Valor } \\
\text { Justo }\end{array}$ & 0 & 0 & 0 & 0 & 1 & 1 & 1 & 2 & 3 & 2 & 3 & 0 & 4 & 1 & 6 & 3 & 2 & 29 \\
\hline Normas sobre Valor Justo & 0 & 0 & 0 & 0 & 1 & 1 & 1 & 2 & 3 & 1 & 1 & 0 & 1 & 0 & 1 & 2 & 1 & 15 \\
\hline $\begin{array}{l}\text { Aplicações das Normas } \\
\text { Contábeis de Valor Justo }\end{array}$ & 0 & 0 & 0 & 0 & 0 & 0 & 0 & 0 & 0 & 1 & 2 & 0 & 3 & 1 & 5 & 1 & 1 & 14 \\
\hline $\begin{array}{l}\text { Efeitos e Relações Internas } \\
\text { às Entidades }\end{array}$ & 1 & 0 & 1 & 4 & 0 & 0 & 3 & 3 & 2 & 3 & 4 & 7 & 1 & 6 & 3 & 3 & 5 & 46 \\
\hline $\begin{array}{l}\text { Efeitos da Aplicação do } \\
\text { Valor Justo em Contas/ } \\
\text { Operações Específicas }\end{array}$ & 0 & 0 & 1 & 0 & 0 & 0 & 0 & 1 & 0 & 2 & 0 & 2 & 0 & 1 & 0 & 2 & 2 & 11 \\
\hline $\begin{array}{l}\text { Efeitos Relacionados às } \\
\text { Escolhas da Administração }\end{array}$ & 0 & 0 & 0 & 1 & 0 & 0 & 2 & 0 & 0 & 0 & 3 & 3 & 0 & 2 & 0 & 0 & 2 & 13 \\
\hline $\begin{array}{l}\text { Comparação do Valor Justo } \\
\text { com outros Métodos de } \\
\text { Avaliação }\end{array}$ & 1 & 0 & 0 & 2 & 0 & 0 & 1 & 1 & 2 & 1 & 1 & 1 & 1 & 3 & 3 & 0 & 0 & 17 \\
\hline $\begin{array}{l}\text { Aplicação do Valor Justo em } \\
\text { Passivos }\end{array}$ & 0 & 0 & 0 & 1 & 0 & 0 & 0 & 1 & 0 & 0 & 0 & 1 & 0 & 0 & 0 & 1 & 1 & 5 \\
\hline $\begin{array}{l}\text { Efeitos e Relações Externas } \\
\text { às Entidades }\end{array}$ & 0 & 0 & 0 & 2 & 2 & 0 & 1 & 1 & 2 & 0 & 0 & 4 & 1 & 3 & 8 & 5 & 7 & 36 \\
\hline $\begin{array}{l}\text { Análise de Riscos e Valor } \\
\text { Justo }\end{array}$ & 0 & 0 & 0 & 0 & 1 & 0 & 0 & 0 & 1 & 0 & 0 & 1 & 0 & 2 & 1 & 1 & 1 & 8 \\
\hline $\begin{array}{l}\text { Reações do Mercado de } \\
\text { Ações ao Valor Justo }\end{array}$ & 0 & 0 & 0 & 2 & 1 & 0 & 1 & 1 & 0 & 0 & 0 & 3 & 0 & 0 & 2 & 3 & 4 & 17 \\
\hline $\begin{array}{l}\text { Relação entre Auditores e } \\
\text { Auditorias e Valor Justo }\end{array}$ & 0 & 0 & 0 & 0 & 0 & 0 & 0 & 0 & 1 & 0 & 0 & 0 & 0 & 1 & 3 & 0 & 1 & 6 \\
\hline $\begin{array}{l}\text { Valor Justo e a Crise } \\
\text { Financeira }\end{array}$ & 0 & 0 & 0 & 0 & 0 & 0 & 0 & 0 & 0 & 0 & 0 & 0 & 1 & 0 & 2 & 1 & 1 & 5 \\
\hline Total Geral & 1 & 0 & 1 & 6 & 3 & 1 & 5 & 6 & 7 & 5 & 7 & 11 & 6 & 10 & 17 & 11 & 14 & 111 \\
\hline
\end{tabular}


De forma geral, observa-se, pela Tabela 1 que, durante os 16 anos analisados, o Macrotema com maior produtividade no período foi o voltado para os efeitos e relações do valor justo internos à entidade, representando 46 (41\%) publicações, seguido por Efeitos e Relações Externas às Entidades, representando 36 (32\%) pesquisas e Normatização do Valor Justo, representando 29 (26\%). A distribuição dos artigos na classificação indica que há uma preocupação maior com a interação da contabilidade por valor justo com o ambiente interno à entidade - esse Macrotema apresenta mais publicações no início da amostra, enquanto os demais são mais presentes nos períodos finais. A distribuição heterogênea dos artigos entre os Macrogrupos sugere que, apesar de haver áreas de maior interesse, dá-se relevância aos diferentes temas de pesquisa, o que indica a amplitude dos estudos sobre fair value e suas aplicações. Outra explicação pode ser observada pela própria tempestividade das publicações. Alguns grupos tendem a ter maior concentração após algum evento específico, como, por exemplo, a crise financeira ou a promulgação da norma, de forma que, naquele momento, dados podem estar disponíveis, ou, até mesmo, o interesse nessas pesquisas aumente devido aos eventos ocorridos.

Vale ressaltar que, apesar de Normatização do Valor Justo ter sido o Macrogrupo com menor número de artigos classificados, Normas sobre Valor Justo e Aplicações das Normas Contábeis de Valor Justo foram os terceiro e quarto Microgrupos mais analisados, representando 14\% e 13\% dos artigos classificados, respectivamente, o que destaca a relevância dos estudos na área.

Em relação aos Microgrupos do macrogrupo Efeitos e Relações Internas às Entidades, Comparação do Valor Justo com outros Métodos de Avaliação reuniu o maior número de artigos classificados (15\%), o que leva a crer que a eficiência, confiabilidade e relevância do valor justo em relação aos demais métodos de avaliação são motivos de interesse na comunidade científica. Dos 17 artigos classificados neste microtema, 12 trabalham com base em comparações entre o fair value e o custo histórico, especificamente, o que denota a relevância de ambos os métodos de avaliação no ambiente contábil, que há décadas têm sido motivos de discussões e debates (Lustosa, 2016).

Dentro do Macrotema Efeitos e Relações Externas às Entidades, o Microgrupo com mais artigos agrupados é Reações do Mercado de Ações ao Valor Justo, tendo 17 (15\%) publicações, demonstrando que o valor justo é motivo de atenção não apenas da contabilidade das entidades, mas também para os diversos stakeholders, já que as mudanças na avaliação do patrimônio das entidades podem afetar diretamente seu valor de mercado, assim como o retorno financeiro dos investimentos, além de outros aspectos, como, por exemplo, a alteração da política de distribuição de dividendos.

Em decorrência dos resultados observados, a Tabela 2 apresenta a distribuição das publicações, a fim de possibilitar a visualização mais facilitada para comparação, segregando em dois períodos de análise 2000 a 2010, e 2011 a 2016. A separação desses períodos visa tentar diferenciar pesquisas pré e pós-crise financeira, uma vez que, como argumentado, essa possui estreita relação com as pesquisas sobre valor justo. Nesse sentido, a despeito de o ápice da crise ser em 2007-08, optou-se pela separação dos grupos temporais, conforme Tabela 2, de forma a absorver o tempo de avaliação das publicações internacionais. 
Tabela 2

Classificação de artigos por Macro e Microgrupos por período. * A.V: Análise vertical

\begin{tabular}{lccccc}
\hline \multicolumn{1}{c}{ Grupos (macro e micro) / ano } & $\mathbf{2 0 0 0 - 2 0 1 0}$ & $\mathbf{A . V . \%}$ & $\mathbf{2 0 1 1 - 2 0 1 6}$ & $\mathbf{A . V . \%}$ & Crescimento \\
\hline Memória de Cálculo & $\mathrm{a}$ & & $\mathrm{b}$ & & $\mathrm{c}=(\mathrm{b}-\mathrm{a}) / \mathrm{a}$ \\
\hline Normatização do Valor Justo & 13 & $31 \%$ & 16 & $23 \%$ & $23 \%$ \\
\hline Normas sobre Valor Justo & 10 & $24 \%$ & 5 & $\mathbf{7} \%$ & $-50 \%$ \\
\hline Aplicações das Normas Contábeis de Valor Justo & 3 & $7 \%$ & 11 & $16 \%$ & $267 \%$ \\
\hline Efeitos e Relações Internas às Entidades & 21 & $50 \%$ & 25 & $36 \%$ & $19 \%$ \\
\hline $\begin{array}{l}\text { Efeitos da Aplicação do Valor Justo em Contas/Operações } \\
\text { Específicas }\end{array}$ & 4 & $10 \%$ & 7 & $10 \%$ & $75 \%$ \\
\hline Efeitos Relacionados às Escolhas da Administração & 6 & $14 \%$ & 7 & $10 \%$ & $17 \%$ \\
\hline $\begin{array}{l}\text { Comparação do Valor Justo com outros Métodos de } \\
\text { Avaliação }\end{array}$ & 9 & $21 \%$ & 8 & $12 \%$ & $-11 \%$ \\
\hline Aplicação do Valor Justo em Passivos & 2 & $5 \%$ & 3 & $4 \%$ & $50 \%$ \\
\hline Efeitos e Relações Externas às Entidades & 8 & $19 \%$ & 28 & $41 \%$ & $250 \%$ \\
\hline Análise de Riscos e Valor Justo & 2 & $5 \%$ & 6 & $9 \%$ & $200 \%$ \\
\hline Reações do Mercado de Ações ao Valor Justo & 5 & $12 \%$ & 12 & $17 \%$ & $140 \%$ \\
\hline Relação entre Auditores e Auditorias e Valor Justo & 1 & $2 \%$ & 5 & $7 \%$ & $400 \%$ \\
\hline Valor Justo e a Crise Financeira & 0 & $0 \%$ & 5 & $7 \%$ & $\mathrm{n} / \mathrm{a}$ \\
\hline Total & 42 & $100 \%$ & 69 & $100 \%$ & $64 \%$ \\
\hline
\end{tabular}

Fonte: elaboração própria.

Como se observa, os Macrogrupos sofreram aumentos médios na produtividade de artigos no período pós-crise, relativo aos anos entre 2011 e 2016, em relação ao período 2000-2010. O Macrogrupo que apresentou maior aumento nas publicações por ano foi Efeitos e Relações Externas às Entidades, com crescimento de $250 \%$ entre os dois períodos, seguido por Normatização do Valor Justo, representando crescimento de 23\%, e, por fim, Efeitos e Relações Internas às Entidades, com crescimento de 19\%.

O maior aumento no percentual das publicações por ano no Macrogrupo Efeitos e Relações Externos às Entidades durante o período pós-crise se deve, principalmente, aos microtemas Relações entre Auditores e Auditorias e Valor Justo (400\%) e Análise de Riscos e Valor Justo (200\%). Sobre esse primeiro Microgrupo, entende-se que seu crescimento pode-se dever à maior exposição do fair value após a crise, tendo gerado interesse dos pesquisados na relação deste com setores específicos da Contabilidade. Além disso, a explicação pode ser decorrente da obrigatoriedade da aplicação do valor justo após a promulgação das normas específicas sobre o assunto (SFAS 157 e IFRS 13), momento no qual a auditoria se deparou explicitamente com a avaliação compulsória a valor justo por parte das entidades. Os demais crescimentos nesse Macrogrupo também podem ser explicados em decorrência de maior preocupação com o valor justo e seus diversos efeitos, como os riscos das entidades e a reação dos participantes do mercado a esses riscos.

Ainda no Macrogrupo Efeitos e Relações Externos às Entidades, outra observação é o crescimento do Microtema Valor Justo e a Crise Financeira, para o qual não se observavam publicações no primeiro período analisado, mas ocorrência de 5 artigos em 2011-2016. A primeira publicação nesse grupo se deu em 2012. Seguindo a lógica da divisão dos anos na tabela, como a crise iniciou-se em 2007/2008, entende-se que essa diferença temporal entre o começo da crise e as publicações pode ser explicada pelo tempo, tanto para coleta de dados e elaboração dos estudos, quanto de publicação nesses journals, que pode demorar até quatro anos, em alguns casos. 
Em relação ao macrotema Efeitos e Relações Internas às Entidades, o Microgrupo com maior crescimento relativo na produção científica anual foi Efeitos da Aplicação do Valor Justo em Contas/ Operações Específicas, com aumento de $75 \%$ nos artigos entre os dois períodos. Tal acréscimo pode estar relacionado ao fato desses estudos terem sua relevância aumentada após a promulgação das normas contábeis. Observa-se, também, uma redução percentual nos estudos sobre Comparação do valor justo com outros métodos de avaliação". Isso se deve ao fato de que o debate sobre a eficiência e relevância do fair value como método de avaliação já se estende há algumas décadas, assim como a comparação do valor justo com outros métodos, principalmente com o custo histórico.

Por fim, com relação ao Macrogrupo Normatização do Valor Justo, o Microgrupo Aplicações das Normas Contábeis de Valor Justo apresentou aumento de 267\%, enquanto Normas sobre Valor Justo teve uma diminuição de 50\%. Uma possível explicação para essas variações deriva da tempestividade entre a promulgação e o ápice da discussão sobre as normas relativas a valor justo, seja por sua aplicabilidade ou na comparação de normas correlatas.

\subsection{Tipologias e métodos de pesquisa dos artigos}

Em relação às Tipologias de pesquisa utilizadas nos artigos da amostra, a classificação se deu em qualitativos e quantitativos por Macro e Microgrupo, conforme Tabela 3.

Tabela 3

Classificação Tipológica dos artigos por Macro e Microgrupos. *A.H: Análise horizontal

\begin{tabular}{|c|c|c|c|c|c|c|}
\hline Grupos (macro e micro) / quali x quant & Quali & A.H & Quan & A.H & Total & A.H \\
\hline Normatização do Valor Justo & 20 & $69 \%$ & 9 & $31 \%$ & 29 & $100 \%$ \\
\hline Normas sobre Valor Justo & 14 & $93 \%$ & 1 & $7 \%$ & 15 & $100 \%$ \\
\hline Aplicações das Normas Contábeis de Valor Justo & 6 & $43 \%$ & 8 & $57 \%$ & 14 & $100 \%$ \\
\hline Efeitos e Relações Internas às Entidades & 16 & $35 \%$ & 30 & $65 \%$ & 46 & $100 \%$ \\
\hline $\begin{array}{l}\text { Efeitos da Aplicação do Valor Justo em Contas/Operações } \\
\text { Específicas }\end{array}$ & 1 & $9 \%$ & 10 & $91 \%$ & 11 & $100 \%$ \\
\hline Efeitos Relacionados às Escolhas da Administração & 5 & $38 \%$ & 8 & $62 \%$ & 13 & $100 \%$ \\
\hline Comparação do Valor Justo com outros Métodos de Avaliação & 6 & $35 \%$ & 11 & $65 \%$ & 17 & $100 \%$ \\
\hline Aplicação do Valor Justo em Passivos & 4 & $80 \%$ & 1 & $20 \%$ & 5 & $100 \%$ \\
\hline Efeitos e Relações Externas às Entidades & 9 & $25 \%$ & 27 & $75 \%$ & 36 & $100 \%$ \\
\hline Análise de Riscos e Valor Justo & 2 & $25 \%$ & 6 & $75 \%$ & 8 & $100 \%$ \\
\hline Reações do Mercado de Ações ao Valor Justo & 4 & $24 \%$ & 13 & $76 \%$ & 17 & $100 \%$ \\
\hline Relação entre Auditores e Auditorias e Valor Justo & 3 & $50 \%$ & 3 & $50 \%$ & 6 & $100 \%$ \\
\hline Valor Justo e a Crise Financeira & 0 & $0 \%$ & 5 & $100 \%$ & 5 & $100 \%$ \\
\hline Total & 45 & $41 \%$ & 66 & $59 \%$ & 111 & $100 \%$ \\
\hline
\end{tabular}

Fonte: elaboração própria.

Em todos os Macrogrupos, há espaço para a realização de pesquisas tanto qualitativas como quantitativas. Observa-se, porém, que a quantidade de artigos que utilizaram a abordagem quantitativa (59\%) foi superior à dos artigos que utilizaram a qualitativa (41\%), sendo essa uma tendência observada em diversas áreas da Contabilidade, que têm se amparado em estudos de cunho positivista com testes de hipóteses de forma quantitativa. 
Em relação aos macro temas, Efeitos e Relações Externas às Entidades apresentou superioridade de estudos quantitativos (75\%). Os demais grupos destacaram-se pelos padrões opostos entre si. Efeitos e Relações Internas às Entidades também apresentou superioridade de estudos quantitativos (65\%); enquanto que em Normatização do Valor Justo, os qualitativos (69\%) eram maioria. Essa diferença se deve ao fato de os estudos no grupo de normatização do valor justo apresentarem natureza amparada em um paradigma mais normativo, enquanto os demais grupos em um paradigma positivista.

Ainda na Tabela 3, observa-se certo balanceamento entre a produção e as abordagens de pesquisa, com alguns Microgrupos apresentando diferenças significativas. Normas sobre Valor Justo apresenta predominância de estudos qualitativos, o que pode ser explicado pela maior ocorrência de estudos com discussões normativas, demonstrando, por exemplo, prós e contras da normatização. Em Aplicação do Valor Justo em Passivos há certo balanceamento.

Em um contraponto, os Microgrupos Efeitos da Aplicação do Valor Justo em Contas/Operações Específicas, Reações do Mercado de Ações ao Valor Justo e Análise de Riscos e Valor Justo apresentaram maioria de estudos com natureza quantitativa. Nesses grupos a justificativa pode se encontrar, principalmente, nas palavras que os definem: efeitos e reações. Mesmo havendo possibilidade de estudos qualitativos, assim como se observa, essas palavras são mais amplamente medidas em pesquisas científicas por meio de testes estatísticos, direcionando as pesquisas a um viés quantitativo. Por fim, o grupo Valor Justo e a Crise Financeira possui representatividade total (100\%) de estudos quantitativos. Isso pode ser explicado, também, pela mensuração dos efeitos da crise por meio de proxies e constructos quantitativos, de forma a medir tais efeitos no valor justo ou vice-versa.

Nesse ponto, observa-se diferentes oportunidades de pesquisa, quais sejam por estudos em temas e abordagens mais carentes, por exemplo, discussões qualitativas sobre a relação entre valor justo e crise financeira. Para subsidiar a compreensão do cenário de métodos utilizados, a Tabela 4 apresenta os estudos separados por métodos e relacionados com a abordagem de pesquisa (qualitativa e quantitativa), realizada com base no framework teórico, adaptado de Smith (2003).

Tabela 4

Classificação Tipológica dos artigos por método

\begin{tabular}{lcccccc}
\hline \multicolumn{1}{c}{ Método } & Qualitativa & A.V.\% & Quantitativa & A.V.\% & Total & A.V.\% \\
\hline Archival & 7 & $16 \%$ & 62 & $94 \%$ & 69 & $62 \%$ \\
\hline Normativo & 15 & $33 \%$ & 0 & $0 \%$ & 15 & $14 \%$ \\
\hline Experimento & 9 & $20 \%$ & 4 & $6 \%$ & 13 & $12 \%$ \\
\hline Estudo de caso & 6 & $13 \%$ & 0 & $0 \%$ & 6 & $5 \%$ \\
\hline Caso de Ensino & 3 & $7 \%$ & 0 & $0 \%$ & 3 & $3 \%$ \\
\hline Framework & 3 & $7 \%$ & 0 & $0 \%$ & 3 & $3 \%$ \\
\hline Revisão de Literatura & 2 & $4 \%$ & 0 & $0 \%$ & 2 & $2 \%$ \\
\hline Total & 45 & $100 \%$ & 66 & $100 \%$ & 111 & $100 \%$ \\
\hline
\end{tabular}

*A.V: Análise vertical

Fonte: elaboração própria.

Predominam estudos com base no método archival. A utilização de grandes bases de dados em pesquisas quantitativas contribui para tal fator, assim como a maior aderência dessas bases para a realização de testes estatísticos robustos. Observa-se, entretanto, que existem estudos desse método classificados como qualitativos, como análise de conteúdo e de discurso que, por natureza, são qualitativos - mas, de acordo com Smith (2003), são classificados como archival por utilizarem dados coletados, ou não, para as análises. 
Ainda, de forma surpreendente, o terceiro método mais representativo é o de experimentos, sendo superado pelos estudos de cunho normativo. A totalidade dos normativos foi classificada como qualitativa, mostrando que há espaço para a realização de estudos quantitativos e normativos. À primeira vista, essa união pode parecer incongruente, porém, observam-se estudos quantitativos relativos a discussões de aplicações normativas ou, até mesmo, para subsidiar sugestões empíricas de mudanças normativas. Os experimentos também são contributivos para a ciência, uma vez que auxiliam na simulação de cenários e pesquisas que poderiam não ser viáveis na economia de forma rotineira.

Os demais métodos demonstram-se menos representativos na amostra, apresentando, portanto, uma possibilidade fértil de aplicação desses para a área de estudos sobre valor justo. O presente estudo, por exemplo, de acordo com Smith (2003), seria classificado como revisão de literatura, sendo o grupo de menor representatividade na amostra. Esse método pode contribuir para o desenvolvimento de pesquisas que sejam subsídios para, além de outros pesquisadores, o mercado e reguladores que podem se valer das análises sobre as pesquisas realizadas e suas contribuições.

Por fim, observa-se que os estudos de natureza quantitativa se restringem a dois métodos de pesquisa: archival e experimentos. Nesse sentido, pesquisas podem observar essa lacuna quanto a aplicação dos métodos e como possibilidade de ampliar os estudos de natureza quantitativa a partir da utilização de outros métodos.

\subsection{Autorias e origens institucionais}

A Tabela 5 apresenta a quantidade de artigos por quantidade de autores, ou seja, a relação do número de colaboradores por publicação, assim como o total de autorias em cada nível de colaboração. Como é possível observar, predominam artigos com participação de três (33\%), duas (32\%) e uma autoria (28\%), com pequena representatividade de colaborações acima de três autores por artigo. O total de autorias apresentado é de 244, sendo a média de autores por artigo de 2,2. Essa média assemelha-se à de demais estudos que aplicam técnicas de análise de autores, como Matos, Niyama, Araújo e Marques (2012) sugerindo que, nesse quesito, o estudo do valor justo segue os padrões das outras temáticas.

Tabela 5

Quantidade de autorias por artigo

\begin{tabular}{|c|c|c|c|c|}
\hline Quant. de Autores por Artigo & Quant. de Artigos & $\%$ & Quant. de Autorias & $\%$ \\
\hline 1 autor & 31 & $28 \%$ & 31 & $13 \%$ \\
\hline 2 autores & 36 & $32 \%$ & 72 & $30 \%$ \\
\hline 3 autores & 37 & $33 \%$ & 111 & $45 \%$ \\
\hline 4 autores & 5 & $5 \%$ & 20 & $8 \%$ \\
\hline 5 autores & 2 & $2 \%$ & 10 & $4 \%$ \\
\hline Total & 111 & $100 \%$ & 244 & $100 \%$ \\
\hline
\end{tabular}

Nota: A coluna "Total de Autores" considerou a ocorrência de autoria em cada publicação, de modo que um mesmo autor, com mais de uma publicação, foi considerado repetidamente por sua ocorrência e, portanto, adicionado mais de uma vez para totalização.

Fonte: elaboração própria.

Em relação à vinculação dos autores, observou-se a instituição a qual os pesquisadores estavam vinculados e em quais países estas são sediadas, a fim de caracterizar a participação de instituições de pesquisa e de países no estudo do valor justo. A Tabela 6 apresenta os países com maior quantidade de autorias nos artigos, baseando-se não na origem de nascimento dos autores, mas, sim, na origem das instituições às quais estão vinculados. 
Tabela 6

Quantidade de autorias por país de vinculação das instituições

\begin{tabular}{|c|c|c|c|c|c|}
\hline País & Quantidade & $\%$ & País & Quantidade & $\%$ \\
\hline Estados Unidos & 164 & $67 \%$ & Singapura & 5 & $2 \%$ \\
\hline Alemanha & 12 & $5 \%$ & Holanda & 4 & $2 \%$ \\
\hline Reino Unido & 9 & $4 \%$ & Coreia do Sul & 3 & $1 \%$ \\
\hline Espanha & 7 & $3 \%$ & Egito & 2 & $1 \%$ \\
\hline Itália & 7 & $3 \%$ & França & 2 & $1 \%$ \\
\hline Austrália & 6 & $2 \%$ & Suíça & 2 & $1 \%$ \\
\hline China & 6 & $2 \%$ & Outros & 5 & $2 \%$ \\
\hline Canadá & 5 & $2 \%$ & \multirow{2}{*}{ Total } & \multirow{2}{*}{244} & \multirow{2}{*}{$100 \%$} \\
\hline Israel & 5 & $2 \%$ & & & \\
\hline
\end{tabular}

Fonte: elaboração própria

Observa-se que os Estados Unidos é o país que mais contém autorias em pesquisas de valor justo, representando, sozinho, $67 \%$ do total, indicando sua grande influência acadêmica no tema. $O$ fato de apenas cinco países concentrarem $82 \%$ das publicações, sendo os EUA ou países europeus, demonstra a possível hegemonia das pesquisas na área, com pequena inserção de autores vinculados a instituições fora do eixo EUA-Europa. Se somados os países da Europa e os EUA, a representatividade do eixo chega a 86\%. Observa-se, ainda, a não representatividade na amostra de países da América Latina.

\subsection{Artigos por periódico}

Por fim, a Tabela 7 apresenta a quantidade de artigos publicados por periódico.

Tabela 7

Quantidade de artigos por periódicos

\begin{tabular}{lcllc}
\hline \multicolumn{1}{c}{ Journal } & Quant & \multicolumn{1}{c}{ Journal } & Quant \\
\hline Review of Accounting Studies & 11 & Critical Perspectives on Accounting & 5 \\
\hline The Accounting Review & 10 & European Accounting Review & 4 \\
\hline Journal of Accounting and Economics & 9 & Journal of Business Finance \& Accounting & 4 \\
\hline Journal of Accounting Research & 8 & Behavioral Research in Accounting & 3 \\
\hline Journal of Accounting, Auditing \& Finance & 8 & Issues in Accounting Education & 3 \\
\hline $\begin{array}{l}\text { ABACUS - A journal of accounting, finance } \\
\text { and business studies }\end{array}$ & 7 & Auditing: A Journal of Practice \& Theory & 2 \\
\hline Accounting and Business Research & 7 & Accounting Historians Journal & 1 \\
\hline Accounting, Organizations and Society & 7 & Journal of International Accounting Research & 1 \\
\hline Contemporary Accounting Research & 7 & $\begin{array}{l}\text { Journal of International Accounting, Auditing and } \\
\text { Taxation }\end{array}$ & 1 \\
\hline Journal of Accounting and Public Policy & 7 & $\begin{array}{l}\text { Journal Of Public Budgeting, Accounting and } \\
\text { Financial Management }\end{array}$ & 1 \\
\hline Accounting Horizons & 5 & Total & 111 \\
\hline
\end{tabular}

Fonte: elaboração própria 
Dos 30 periódicos selecionados com base no trabalho de Matherly e Shortridge (2009), 29 se tornaram objeto de análise do trabalho (cf. Seção 3). Com base nisso, 21 apresentaram publicações sobre fair value entre 2000 e 2016, indicando que o interesse pela pesquisa do valor justo é disseminado em grande parte da comunidade acadêmica. Dos cinco periódicos com mais publicações sobre fair value, quatro estão no topo da lista dos mais relevantes, segundo Matherly e Shortridge (2009), sendo que estes representam 34\% dos artigos publicados, que são: Review of Accounting Studies, The Accounting Review, Journal of Accounting and Economics e Journal of Accounting Research. Tal fato ratifica a importância do estudo de valor justo no meio acadêmico-contábil, demonstrando que a pesquisa sobre o tema é relevante nos journals considerados de maior qualidade na produção científica.

\section{Considerações Finais}

O presente estudo teve o papel de mapear a pesquisa recente sobre fair value para auxiliar o entendimento do tema. Com base nos resultados, a área se mostrou ampla, com diversas temáticas abordadas e com publicações ao longo de todo o período analisado (2000-2016), porém ainda com limitações no uso de métodos e de temáticas. Os principais focos de pesquisa foram (i) a comparação do valor justo com outros métodos de avaliação, demonstrando que o fair value não é consenso no meio acadêmico, e (ii) as reações do mercado de ações ao valor justo, denotando a preocupação dos pesquisadores com a utilização prática e como o mercado interage com o método. Apesar disso, poucas dessas pesquisas se mostram propositivas de mudanças, sendo a maior parte descritiva dos efeitos das mudanças já realizadas.

O estudo da normatização do valor justo representa quase um quarto de todas as publicações analisadas, demonstrando o grande impacto das expedições recentes do Iasb e Fasb sobre o tema na comunidade científica. Outro grande foco de estudos foi a relação do valor justo com o mercado de ações, considerando que esses dois se afetam em ambos os sentidos - naturalmente, a discussão sobre a relação do fair value com a crise financeira tem crescido no período pós-crise, tendo em vista a exposição que essa abordagem ganhou desde então.

Com relação aos métodos, a maioria das publicações foi classificada por utilizar o archival, sendo as pesquisas também de maioria quantitativa. Esse resultado denota a necessidade de ampliar a aplicação de diferentes métodos e abordagens, a fim de fomentar diferentes resultados e visões sobre o valor justo. Ainda, em uma análise de autoria e instituições das publicações, observa-se, mais uma vez, certos padrões já presentes na pesquisa em contabilidade. A supremacia da autoria vinculada a instituições norte-americanas se mostra presente na amostra, fato que pode ser justificado pela língua materna, por força acadêmica da área e outras questões. Da forma atual, pesquisas aplicadas no mercado dos EUA tendem a enviesar, inclusive, a normatização contábil em prol desse mercado, de forma que os demais podem apresentar efeitos diversos e não comparáveis.

Como resumo dos resultados, as pesquisas sobre valor justo se apresentaram em um processo de crescimento nos últimos 16 anos, com destaque a partir de 2006 - o que pode ter relação com o fato de ter sido esse o ano da publicação da SFAS 157, que trata especificamente sobre o tema e engloba conceitos e regras que estavam espalhados por diversas normas até então. Outro destaque nas publicações sobre o tema é posterior à crise financeira de 2007/08, sendo as atenções voltadas para o fair value por conta de sua possível relação com a crise.

Apesar dos pontos citados e da percepção de aumento dos estudos, os resultados demonstram possibilidades de pesquisas futuras. Como o valor justo muitas vezes é relacionado com crises financeiras, estudos de natureza mais propositiva e menos diagnósticos podem ser realizados sobre o tema, incluindo estudos de natureza crítica. Além disso, há ampla relação entre valor justo e instituições financeiras, mas poucos estudos na área de banking foram identificados na amostra, sendo essa uma área de contribuição para a contabilidade e para o mercado. 
Há, ainda, uma carência de estudos que relacionam valor justo com sistemas de controle gerenciais, seja no âmbito interno das entidades, seja externo, como, por exemplo, possíveis influências desses sistemas nos riscos percebidos nos negócios. Há também a carência de estudos de modelagem, relações culturais e proposição de métodos de valuation com base em valor justo. Todas essas propostas podem ser realizadas por abordagens quantitativas ou qualitativas, assim como por diferentes métodos de pesquisa, fora o mainstream archival que vem sendo realizado.

\section{Referências}

Barlev, B. \& Haddad, J. R. (2007) Harmonization, Comparability, and Fair Value Accounting. Journal of Accounting, Auditing \& Finance, 22(3), p. 493-509. DOI: https://doi.org/10.1177/0148558X0702200307

Barth, M. E. (2007). Research, Standard Setting, and Global Financial Reporting. Foundations and Trends ${ }^{\bullet}$ in Accounting, 1(2), p. 71-165. DOI: https://doi.org/10.1561/1400000002

Beatty, A. \& Weber, J. (2006). Accounting Discretion in fair Value Estimates: An Examination of SFAS 142 Goodwill Impairments. Journal of Accounting Research, 44(2), p. 258-288. DOI: https://doi. org/10.1111/j.1475-679X.2006.00200.x

Blacconiere, W. G., Frederickson, J. R., Johnson, M. F. \& Lewis, M. F. (2011). Are voluntary disclosures that disavow the reliability of mandated fair value information informative or opportunistic?. Journal of Accounting and Economics, 52(2-3), p. 235-251. DOI: https://doi.org/10.1016/j.jacceco.2011.09.002

Bolívar, M. P. R. \& Galera, A. N. (2012). The Role of fair Value Accounting in Promoting Government Accountability. Abacus, 48(3), p. 348-386. DOI: https://doi.org/10.1111/j.1467-6281.2011.00352.x

Bowen, R. M. \& Khan, U. (2014). Market reactions to policy deliberations on fair value accounting and impairment rules during the financial crisis of 2008-2009. Journal of Accounting and Public Policy, 33(3), p. 233-259. DOI: 10 https://doi.org/.1016/j.jaccpubpol.2014.02.003

Brink, A. G., Tang, F., \& Yang, L. (2016). The Impact of Estimate Source and Social Pressure on Auditors' Fair Value Estimate Choices. Behavioral Research in Accounting, 28(2), 29-40. DOI: https://doi. org/10.2308/bria-51457

Bryan, S. \& Lilien, S. (2013). How Fair Values and Accounting Structures Allow Triple-Counting Income: Implications for Standard Setters, Market Participants, and Academics. Journal of Accounting, Auditing \& Finance, 28(1), p. 79-98. DOI: https://doi.org/10.1177/0148558X12468130

Cantrell, B. W., Mclnnis, J. M. \& Yust, C. G. (2014). Predicting Credit Losses: Loan Fair Value versus Historical Costs. The Accounting Review, 89(1), p. 147-176. DOI: http://dx.doi.org/10.2308/accr-50593

Chen, W., Tan, H. T. \& Wang, E. Y. (2013). Fair Value Accounting and Managers' Hedging Decisions. Journal of Accounting Research, 51(1), p. 67-103. DOI: https://doi.org/10.1111/j.1475-679X.2012.00468.x

Christensen, H. B. \& Nikolaev, V. V. (2013). Does fair value accounting oF non-financial assets pass the market test?. Review of Accounting Studies, 18(3), p. 734-775. DOI: https://doi.org/10.1007/s11142-013-9232-0

Danbolt, J. \& Rees, W. (2008). An Experiment in Fair Value Accounting: UK Investment Vehicles. European Accounting Review, 17(2), p. 271-303. DOI: https://doi.org/10.1080/09638180701819865

Elad, C. (2004). Fair value accounting in the agricultural sector: some implications for international accounting harmonization. European Accounting Review, 13(4), p. 621-641. DOI: https://doi.org/10 $.1080 / 0963818042000216839$

Ettredge, M. L., Xu, Y. \& Yi, H. S. (2014). Fair Value Measurements and Audit Fess: Evidence from the Banking Industry. Auditing: A Journal of Practice \& Theory, 33(3), p. 33-58. DOI: https://doi. org/10.2308/ajpt-50701 
Galdini, S. \& Grossi, G. (2014). Voluntary Adoption of the Consolidated Financial Statement and Fair Value Accounting by Italian Local Governments. Journal of Public Budgeting, Accounting and Financial Management, 26(2), p. 313-344.

Gaynor, L. M., Mcdaniel, L. \& Yohn, T. L. (2011). Fair value accounting for liabilities: The role of disclosures in unraveling the counterintuitive income statement effect from credit risk changes. Accounting, Organizations and Society, 36(3), p. 125-134. DOI: https://doi.org/10.1016/j.aos.2011.03.004

Goh, B. E., Li, D., Ng, J. \& Young, K. (2015). O. Market pricing of banks' fair value assets reported under SFAS 157 since the 2008 financial crisis. Journal of Accounting and Public Policy, 34(2), p. 129-218. DOI: https://doi.org/10.1016/j.jaccpubpol.2014.12.002

Goncharov, I., Riedl, E. J. \& Sellhorn. (2014). Fair value and audit fess. Review of Accounting Studies, 19(1), p. 210-241. DOI: https://doi.org/10.1007/s11142-013-9248-5

Goncharov, I. \& Triest, S. (2011). Do fair value adjustments influence dividend policy?. Accounting and Business Research, 41(1), p. 51-68. DOI: https://doi.org/10.1080/00014788.2011.549637

Goncharov, I. \& Triest, S. (2014). Unintended Consequences of Changing Accounting Standards: The Case of Fair Value Accounting and Mandatory Dividends. ABACUS, 50(3), p. 341-367. DOI: https://doi.org/10.1111/abac.12033

Gray, R. P. (2003). Research Note: Revisiting Fair Value Accounting-Measuring Commercial Banks' Liabilities. Abacus, 39(2), p. 147-272. DOI: https://doi.org/10.1111/1467-6281.t01-1-00129

Griffin, J. B. (2014). The Effects of Uncertainty and Disclosure on Auditors' Fair Value Materiality Decisions. Journal of Accounting Research, 52(5), p. 1165-1193. DOI: https://doi.org/10.1111/1475$-679 X .12059$

Hirst, D. R., Hopkins, P. E. \& Wahlen, J. M. (2004). Fair values, income measurement, and bank analysts' risk and valuation judgements. The Accounting Review, 79(2), p. 453-472. DOI: https://doi. org/10.2308/accr.2004.79.2.453

Israeli, D. (2015). Recognition versus disclosure: evidence from fair value of investment property. Review of Accounting Studies, 20(4), 1457-1503. DOI: https://doi.org/10.1007/s11142-015-9335-x

Iudícibus, S. \& Martins, E. (2007). Uma investigação e uma proposição sobre o conceito e o uso do valor justo. Revista Contabilidade \& Finanças USP, 18, p. 9-18. DOI: https://doi.org/10.1590/S151970772007000300002

Iudícibus, S., Martins, E. \& Carvalho, L. N. (2005). Contabilidade: aspectos relevantes da epopéia de sua evolução. Revista Contabilidade \& Finanças USP, 38, p. 7-19. DOI: https://doi.org/10.1590/S151970772005000200002

Jarva, H. (2009). Do Firms Manage Fair Value Estimates? An Examination of SFAS 142 Goodwill Impairments. Journal of Business Finance \& Accounting, 36(9), p. 1059-1086. DOI: https://doi.org/10.1111/ j.1468-5957.2009.02169.x

Jiang, J., Wang, I. Y. \& Xie, Y. (2015). Does it matter who serves on the Financial Accounting Standards Board? Bob Herz's resignation and fair value accounting for loans. Review of Accounting Studies, 20(1), p. 371-394. DOI: https://doi.org/10.1007/s11142-014-9301-z

Khurana, I. K. \& Kim, M. S. (2003). Relative value relevance of historical cost vs. fair value: Evidence from bank holding companies. Journal of Accounting and Public Policy, 22(1), p. 19-42. DOI: https://doi. org/10.1016/S0278-4254(02)00084-4

Koonce, L., Nelson, K. K. \& Shakespeare, C. M. (2011). Judging the Relevance of Fair Value for Financial instruments. The Accounting Review, 86(6), p. 2075-2098. DOI: https://doi.org/10.2308/accr-10134 
Lachmann, M., Stefani, U. \& Wohrmann, A. (2015). Fair value accounting for liabilities: Presentation format of credit risk changes and individual information processing. Accounting, Organizations and Society, 41, p. 21-38. DOI: https://doi.org/10.1016/j.aos.2014.08.001

Liang, L. \& Riedl, E. J. (2014). The Effect of Fair Value versus Historical Cost Reporting Model on Analyst Forecast Accuracy. The Accounting Review, 89(3), p.1151-1177. DOI: https://doi.org/10.2308/accr50687

Lilien, S., Sarath, B. \& Schrader, R. (2013). Normal Turbulence or Perfect Storm? Disparity in Fair Value Estimates. Journal of Accounting, Auditing \& Finance, 28, (2), p. 192-211. DOI: https://doi. org/10.1177/0148558X13479693

Linsmeier, T. J. (2013). A Standard setter's framework for selecting between fair value and historical cost measurement attributes: a basis for discussion of "Does fair value accounting for nonfinancial assets pass the market test?". Review of Accounting Studies, 18(3), p. 776-782. DOI: https://doi.org/10.1007/ s11142-013-9238-7

Lustosa, P. R. B. (2016). A (In?) Justiça do Valor Justo: SFAS 157, Irving Fisher e GECON. Revista Evidenciação Contábil \& Finanças, 5(1), p. 5-21. doi: 10.18405/recfin20170101

Magnan, M., Menini, A. \& Parbonetti, A. (2015). Fair value accounting: information or confusion for financial markets?. Review of Accounting Studies, 20(1), p. 559-591. DOI: https://doi.org/10.1007/ s11142-014-9306-7

Markarian, G. (2014). The crisis and fair values: echoes of early twentieth century debates?. Accounting Historians Journal, 41(1), p. 35-60.

Marra, A. (2016). The Pros and Cons of Fair Value Accounting in a Globalized Economy. Journal of Accounting, Auditing \& Finance, 31(4), p. 582-591. DOI: https://doi.org/10.1177/0148558X16667316

Martins, E. (2000). Avaliação de Empresas: da Mensuração Contábil à Econômica. Caderno de Estudos, 13(24), p. 28-37.

Matherly, M. \& Shortridge, R. T. (2009). A pragmatic model to estimate journal quality in accounting. Journal of Accounting Education, 27(1), p. 14-29. DOI: https://doi.org/10.1016/j.jaccedu.2009.07.001

Matos, E. B. S., Niyama, J. K., Araújo Neto, L. M. \& Marques, M. M. (2012). Congresso ANPCONT: análise bibliométrica descritiva e avaliativa dos artigos publicados de 2007 a 2011. Enfoque: Reflexão Contábil, 31(3), p. 73-88. DOI: https://doi.org/10.4025/enfoque.v31i3.16946

Niyama, J. K.; \& Silva, C. A. T. (2008). Teoria da Contabilidade. São Paulo, Atlas.

Palea, V. (2015). The political economy of fair value reporting and the governance of the standards-setting process: Critical issues and pitfalls from a continental European Union perspective. Critical Perspectives on Accounting, 29(1), p. 1-15. DOI: https://doi.org/10.1016/j.cpa.2014.10.004

Paré, G., Trudel, M., Jaana, M. \& Kitsiou, S. (2015). Synthesizing information systems knowledge: A typology of literature reviews. Information \& Management, 52(2), p. 183-199. DOI: https://doi. org/10.1016/j.im.2014.08.008

Quagli, A. \& Avallone, F. (2010). Fair Value or Cost Model? Drivers of Choice for IAS 40 in the Real Estate Industry. European Accounting Review, 19(3), p. 461-493. DOI: https://doi.org/10.1080/09638 180.2010.496547

Richard, J. (2005). The concept of fair value in French and German accounting regulations from 1673 to 1914 and its consequences for the interpretation of the stages of development of capitalist accounting. Critical Perspectives on Accounting, 41(5), p. 825-850. DOI: https://doi.org/10.1016/j. cpa.2003.06.008 
Robinson, D. \& Burton, D. (2004). Discretion in Financial Reporting: The Voluntary Adoption of fair Value Accounting for Employee Stock Options. Accounting Horizons, 18(2), p. 97-108. DOI: https:// doi.org/10.2308/acch.2004.18.2.97

Smith, M. (2003). Research Methods in Accounting. London, UK: Sage Publications.

So, S. \& Smith, M. (2009). Value-relevance of presenting changes in fair value of investment properties in the income statement: Evidence from Hong Kong. Accounting and Business Research, 39(2), p. $103-$ 118. DOI: https://doi.org/10.1080/00014788.2009.9663352

Song, C. J. \& Thomas, W. B.; Yi, H. (2010). Value Relevance of FAS No. 157 Fair Value Hierarchy Information and the Impact of Corporate Governance Mechanisms. The Accounting Review, 85(4), p. 1375-1410. DOI: https://doi.org/10.2308/accr.2010.85.4.1375

Valencia, A., Smith, T. J. \& Ang, J. (2013). The Effect of Noisy Fair Value Measures on Bank Capital Adequacy Ratios. Accounting Horizons, 27(4), 693-710. DOI: https://doi.org/10.2308/acch-50517

Whittington, G. (2008). Fair Value and the IASB/FASB Conceptual Framework Project: An Alternative View. Abacus, 44(2), p. 139-168. DOI: https://doi.org/10.1111/j.1467-6281.2008.00255.x

Wu, W., Thibodeau, N. \& Couch, R. (2016). An Option for Lemons? The Fair Value Option for Liabilities During the Financial Crisis. Journal of Accounting, Auditing \& Finance, 31(4), 441-482. DOI: https://doi.org/10.1177/0148558X16645994 